\title{
KARAKTERISTIK HABITAT TEMPAT BERTELUR PENYU SISIK (Eretmochelys imbricata) DI TAMAN WISATA ALAM TANJUNG KELUANG KECAMATAN KUMAI KALIMANTAN TENGAH
}

\author{
(Characteristics Of The Habitat Laying Hawksbill Turtle (Eretmochelys imbricata) In Tanjung \\ Keluang Nature Park District Kumai Central Kalimantan)
}

\author{
Muhamad Nur Karim, Slamet Rifanjani, Sarma Siahaan \\ Fakultas Kehutanan Universitas Tanjungpura Pontianak, Jl. Daya Nasional Pontianak 78124 \\ E-mail : mnurkarim2011@gmail.com
}

\begin{abstract}
This research aimed to discover the characteristics of hawksbill turtle egg-laying place (Eretmochelys imbricata) in the Tanjung Keluang Nature Park of Kumai District Central Kalimantan. The data which is collected to describe the characteristics of the habitat covers the length of the beach, its width, its slope, the distance of the nest with the vegetation, the air humidity, the air temperature, the nest temperature, the moisture content of sand substrate, the texture of sand substrate, the water salinity, and other factors that threaten the hawksbill turtle egg-laying place habitat. From the location of the study, it was found that the length of the beach that becomes the egg-laying place is 5000 meters and 1200 meters that do not become the egg-laying place, the beach width is about $3-12$ meters at the highest tide and $9-20$ meters at the lowest tide, the slope of the beach where the nest is found ranges from 10 to $15 \%$ and $8-11 \%$ where the nest cannot be found, the nest distance with the vegetation is about $0-2$ meters, the air humidity is around 94,7\% - 68,8\%, the air temperature is about $28,83^{\circ} \mathrm{C}-33^{\circ} \mathrm{C}$, the nest temperature is about $28,62^{\circ} \mathrm{C}$, the sand substrate texture is medium with 0,21-0,50 $\mu m$, and the sea water salinity is $27,5 \%$. At the location of the study there was found that every hawksbill turtle nest located in a shade of sea pandan trees (Pandanus tectorius). Hawksbill turtles are threatened by predators such as monitor lizards (Varanus salvator), ghost crabs (Ocypoda sp), fishing activities, waste bins, and natural factors such as coastal abrasion and the presence of weeds growing on the beach surface.
\end{abstract}

Keyword: Habitat Characteristics, Hawksbill turtle, Tanjung Keluang Natural Park

\section{PENDAHULUAN}

Taman Wisata Alam Tanjung Keluang merupakan areal pantai yang ditunjuk sebagai Taman Wisata Alam berdasarkan Surat Keputusan Menteri Kehutanan No. 046/Kpts-II/1984 tanggal 12 Maret 1984 dan menyimpan jenis - jenis langka seperti penyu sisik. Taman Wisata Alam Tanjung Keluang mempunyai luas lebih dari 2000 ha, dengan karakteristik lokasi seperti mempunyai hamparan pasir putih yang luas, laut yang tenang serta terdapat tumbuhan khas pantai seperti bakau, pidada, api-api, nipah, nirih, pandan laut, cemara laut, kelapa, ketapang serta tumbuhan formasi pes-caprae, seperti kangkung - kangkungan, kacang laut, rumput teki, rumput gulung yang diselingi tanaman pionir dan tumbuhan dari ciri ekosistem lain.

Kawasan TWA Tanjung Keluang merupakan salah satu lokasi yang menjadi tempat peneluran bagi Penyu 
Sisik (Eretmochelys imbricata) yang menjadi salah satu daya tarik wisata kawasan ini. Penyu sisik merupakan salah satu dari jenis penyu di Indonesia yang dilindungi berdasarkan Surat Keputusan Menteri Kehutanan No. 882/Kpts-II/1992 bersama dengan penyu pipih, juga berdasarkan Peraturan Menteri Lingkungan Hidup Dan Kehutanan No P. 92 Tahun 2019 Tentang Jenis Tumbuhan Dan Satwa Dilindungi. Untuk menjaga kelestarian serta menjaga keberadaan penyu sisik di Kawasan TWA Tanjung Keluang maka diperlukan pengkajian terkait karakteristik habitat tempat bertelur bagi penyu sisik di lokasi tersebut.

Tujuan dari penelitian ini adalah untuk mendata karakteristik habitat tempat bertelur penyu sisik (Eretmochelys imbricata) di Taman Wisata Alam Tanjung Keluang Kecamatan Kumai Kalimantan Tengah.

\section{METODE PENELITIAN}

Penelitian dilaksanakan dari tanggal 5 Juni - 16 Juli 2016. Peralatan yang digunakan antara lain: peta lokasi penelitian, kamera, termometer, higrometer, meteran tanah, GPS (Global Positioning System), klinometer, conductivity, saringan 4 tingkat, headlamp, botol plastik, botol kaca serta alat tulis.

Metode yang digunakan adalah metode deskriptif dengan teknik observasi secara langsung di lapangan. Observasi lapangan dilakukan untuk melihat kondisi areal penelitian pada bekas sarang penyu sisik (Eretmochelys imbricata) yang dijadikan sebagai lokasi pengamatan. Analisis data dilakukan untuk mencari hubungan secara deskriptif antara habitat yang khas baik dari kondisi fisik, biotik, maupun adanya gangguan yang teridentifikasi dengan penyu sisik yang mendarat dan bertelur di sepanjang pantai.

\section{HASIL DAN PEMBAHASAN}

TWA Tanjung Keluang merupakan kawasan yang dipilih oleh penyu sisik menjadi lokasi peneluran. Pengamatan dilakukan berdasarkan sarang lama dari penyu sisik. TWA Tanjung Keluang mempunyai areal seluas 2580,8 Ha, panjang pantai peneluran \pm 5000 meter, dan mempunyai karakteristik pasir putih serta sebagai lokasi bagi penyu sisik (Eretmochelys imbricata) untuk bertelur. Keberadaan penyu sisik pada lokasi TWA Tanjung Keluang menjadikan daya tarik bagi wisatawan untuk melihat bentuk dan rumah penangkaran bagi tukik - tukik penyu sisik.

Program pelestarian penyu di Taman Wisata Alam Tanjung Keluang Kabupaten Kotawaringin Barat Provinsi Kalimantan Tengah dimulai sejak adanya kegiatan survey populasi penyu yang diprakarsai oleh tim survey populasi penyu BKSDA Kalimantan Tengah. Kegiatan tersebut berguna untuk mengetahui dan memastikan keberadaan habitat penyu dan aktivitas penelurannya dikawasan Taman Wisata Alam Tanjung Keluang hasil dari informasi yang banyak beredar dimasyarakat tentang adanya aktivitas ilegal jual beli telur penyu di desa 
sekitar, hasil pencurian telur - telur penyu di sepanjang pantai TWA Tanjung Keluang. Berdasarkan informasi tersebut, maka BKSDA membentuk tim yang berjumlah 8 orang terdiri atas 4Pengendali Ekosistem Hutan (PEH), 2 Polisi Hutan dan 2Staf resort TWA Tanjung Keluang untuk mencari induk penyu yang akan bertelur selama 3 hari sejak tanggal 25s/d 27 April 2011. Pada hari ke2 tanggal 26 April 2011, sekitar pukul 18.30 WIB pada titik koordinat 0578539-9678872 telah berhasil menemukan seekor induk betina penyu jenis sisik (Eretmochelys imbricata) yang sedang beraktivitas mendarat untuk bertelur di pantai. Hasil temuan seekor induk penyu sisik yang bertelur menjadi cikal bakal dimulainya TWA Tanjung Keluang sebagai wadah penetasan, pembesaran, pelepasan juga pendidikanpelestaraian konservasi penyu, hingga saat ini.

\section{Kondisi fisik pantai}

Kondisi pantai TWA Tanjung keluang merupakan pantai yang tidak terlalu lebar dan luas. Memiliki vegetasi cemara laut (Casuarina equisetifolia) di sepanjang pantai serta pandan laut (Pandanus tectorius) yang sering dijadikan naungan bagi sarang penyu sisik.

Tabel 1. Kondisi Fisik Pantai Taman Wisata Alam Tanjung Keluang (Physical Condition of Tanjung Keluang Beach Nature Park)

\begin{tabular}{lcccc}
\hline No & Parameter & \multicolumn{2}{c}{ Nilai Parameter } & \multirow{2}{*}{ Satuan } \\
\cline { 2 - 4 } & & Terdapat Sarang & Tidak Terdapat & \\
\hline $\mathbf{1}$ & Panjang Pantai & 5000 & 1200 & Meter \\
$\mathbf{2}$ & Kemiringan Pantai & $10-15$ & $8-11$ & $\%$ \\
$\mathbf{3}$ & Jarang Sarang dengan vegetasi & $0-2$ & - & Meter \\
$\mathbf{4}$ & Air Pasang Tertinggi & $3-12$ & $0-3$ & Meter \\
$\mathbf{5}$ & Air surut Terendah & $9-20$ & $5-11$ & Meter \\
\hline
\end{tabular}

Berdasarkan pengukuran di lapangan panjang pantai yang menjadi lokasi peneluran di TWA Tanjung Keluang hingga mercusuar adalah 5000 meter, sedangkan yang tidak menjadi lokasi peneluran adalah 1200 meter. Pantai yang panjang ini sangat cocok dengan kebiasaan penyu untuk memilih lokasi sebagai habitat tempat bertelurnya di tempat luas dan lapang (Nuitja, 1992). Kemiringan pantai pada lokasi penelitian berkisar antara $10-15 \%$. Pantai yang landai berkisaran antara $8-15 \%$ dapat memudahkan penyu sisik untuk mencapai tempat peneluran. Pada saat air surut terendah $9-20$ meter adapun pada saat air pasang tertinggi sebesar $3-12$ meter.
Pada lokasi yang tidak terdapat sarang penyu sisik, kemiringan pantai masih tergolong landai namun pada permukaan pantai telah ditumbuhi rumput liar dan pada saat air pasang permukaan pantai terendam seluruhnya sehingga tidak memungkinkan bagi penyu sisik untuk membuat sarang. Pada umumnya tempat pilihan penyu bertelur merupakan pantai yang luas dan landai serta terletak di bagian atas pantai atau di atas garis pasang tertinggi. Penyu sisik menghemat energi pada malam hari dengan cara memanfaatkan air pasang untuk mencapai area yang kering (supratidal) baru kemudian membuat sarang dan bertelur. 
Jarak sarang penyu sisik yang teridentifikasi di lokasi pengamatan berkisar antara 0 sampai 2 meter dari vegetasi yang ada di bibir pantai. Letak sarang penyu sisik di lokasi penelitian dekat dengan naungan terutama jenis pandan laut (Pandanus tectorius). Keberadaan vegetasi pandan laut berfungsi untuk menjaga suhu sarang dan kelembaban serta akar dari pohon pandan tersebut dapat membantu mencegah longsor pada sarang saat proses penggalian sarang.

\section{Suhu dan kelembaban Udara}

Suhu udara pada saat penelitian pada pukul 06.00 dengan rerata sebesar $28,83^{\circ} \mathrm{C}$ sedangkan pada pukul 12.00 dengan rerata $33,0^{\circ} \mathrm{C}$ dan pada pukul 18.00 dengan rerata $30,08^{\circ} \mathrm{C}$. Dari hasil tersebut suhu tertinggi dicapai pada pukul 12.00 dan suhu terendah dicapai pada pukul 06.00. Kelembaban udara pada lokasi penelitian diperoleh rata-rata pada pukul 06.00 sebesar 94,7\%, pada pukul 12.00 sebesar $68,8 \%$ dan pada pukul 18.00 sebesar $78,8 \%$. Suhu udara dapat berpengaruh terhadap suhu sarang penyu, karena besar kecilnya suhu udara akan mempengaruhi suhu didalam sarang, sehingga ada keterkaitan antara suhu udara dan suhu di dalam sarang penyu, selain itu penyu akan naik kedarat pada suhu dan kelembaban udara yang stabil yaitu pada saat malam hari.

\section{Suhu Sarang}

Suhu pasir sarang merupakan perpaduan antara suhu lingkungan dengan suhu telur selama masa inkubasi suhu sarang pada lokasi penelitian didapatkan rata rata suhu sarang sebesar $28,62^{\circ} \mathrm{C}$.
Menurut Yusuf (2000) dalam Setiawan (2018) suhu sarang akan sangat mempengaruhi jenis kelamin tukik yang di tetaskan, apabila suhu sarang kurang dari $29^{\circ} \mathrm{C}$ maka tukik yang berhasil menetas akan berkelamin jantan, sedangkan apabila lebih dari $29^{\circ} \mathrm{C}$ maka tukik yang akan dihasilkan berjenis kelamin betina. Berdasarkan hal tersebut dapat dilihat bahwa kondisi suhu sarang di lokasi penelitian adalah kurang dari $29^{\circ} \mathrm{C}$ sehingga kemungkinan besar jenis kelamin tukik adalah jantan. Kondisi serupa juga terjadi pada peneluran penyu sisik di Pulau Gelang Karimun Jawa dengan suhu sarang sebesar $\quad 26^{\circ} \mathrm{C}$,(Richayasa, 2015). Perkembangan suhu secara teratur dan bertahap pada batas-batas suhu $25-35^{\circ} \mathrm{C}$ akan menghasilkan laju tetas yang baik dan waktu pengeraman yang relative singkat (Ewart, 1979).

\section{Salinitas air}

Dari hasil penelitian yang dilakukan mendapatkan hasil salinitas air sebesar $27,5 \%$ dan suhu air sebesar $25^{\circ} \mathrm{C}$. Hal ini menunjukkan bahwa keadaan air di lokasi penelitian berkategori air payau. Salinitas penting bagi kelangsungan hidup organisme, hampir semua organisme laut hanya dapat hidup pada daerah yang mempunyai perubahan salinitas yang kecil (Hutabarat dan Evans, 2001). Pada penelitian di lokasi Taman Nasional Bukit Barisan Selatan (TNBBS) Tanggamus Pesisir Barat, didapatkan hasil salinitas air laut sebesar 30,5\%, dan berbeda dengan hasil penelitian ini.

Nilai salinitas air untuk perairan laut berkisar antara 30 - 35\%o (Rahma, 2012) dalam (Rohim , 2017)namun untuk di 
lokasi penelitian berkategori air payau. Kondisi air yang berkategori payau tersebut tidak menjadi faktor penurunan peneluran bagi penyu sisik, karena semakin tinggi salinitas air laut pada pantai peneluran maka akan mengurangi kemungkinan sebuah pantai menjadi lokasi peneluran. Konsentrasi organik material yang sangat tinggi pada pasir di sekitar sarang akan menyebabkan ketidaknormalan pada proses pertukaran air dan memicu kehilangan berat telur sehingga dapat berpengaruh terhadap kesuksesan penetasan (Suciwati, 2012) dalam (Rohim, 2017).

\section{Substrat pasir}

Berdasarkan hasil pengamatan pasir pantai peneluran penyu di Kawasan Wisata Alam Tanjung Keluang memiliki butiran pasir berukuran sedang berkisar antara 0,21 - 0,50 $\mu \mathrm{m}$.. Kondisi substrat pasir di TWA Tanjung Keluang sesuai dengan kondisi pasir pada lokasi peneluran penyu sisik yang berbeda di Pulau Gelang Karimunjawa berukuran pasir sedang $(0,21-0,50 \mu \mathrm{m})$.

Tabel 2. Klasifikasi Pasir (Sand clasification)

\begin{tabular}{lll}
\hline NO & Klasifikasi & Diameter Pasir $(\mu \mathrm{m})$ \\
\hline 1 & Sangat halus & $0,053-0,10$ \\
2 & Halus & $0,10-0.21$ \\
3 & Sedang & $0,21-0,50$ \\
4 & Kasar & $0,50-1,00$ \\
5 & Sangat kasar & $1,00-2,00$ \\
\hline
\end{tabular}

Pasir dengan klasifikasi sedang memungkinkan untuk penyu sisik bersarang karena butiran pasir yang sedang memudahkan bagi penyu untuk penggalian dalam pembuatan sarang. Selain itu kandungan pasir yang tinggi akan menyimpan suhu yang hangat bagi penetasan telur penyu, sehingga jenis pasir sedang kemungkinan menyebarkan suhu yang lebih merata dan stabil (Nuitja, 1992) dalam (Setyawatiningsih, 2011).

\section{Kadar air substrat pasir}

Besarnya nilai kadar air substrat sarang mempengaruhi lama periode bertelur penyu. kadar air substrat yang terlalu rendah menyebabkan keluarnya air dalam telur sedangkan kadar air substrat yang lebih tinggi menyebabkan tumbuhnya bakteri patogen dari cangkang telur (Silalahi,1990) dalam (Syamsuni, 2005). Pada lokasi penelitian nilai kadar air didapatkan nilai rata rata sebesar $3,46 \%$, dengan sampel yang digunakan adalah bagian dasar sarang atau pada kedalaman $45 \mathrm{~cm}$.

Menurut Limpus (1995) dalam (Syamsuni, 2005), bahwa telur yang diinkubasi dalam pasir dengan kadar air 3-12 \% mempunyai perkembangan embrio yang normal. Kadar air susbstrat pasir sangat dipengaruhi oleh suhu udara serta keberadaan sarang dengan vegetasi serta jarak antara sarang dengan batas pasang surut tertinggi.

\section{Kondisi biotik pantai}

Kondisi biotik pantai TWA Tanjung Keluang merupakan pantai yang dihuni oleh berbagai jenis hewan dan tumbuhan. Tumbuhan yang hidup di lokasi penelitian adalah tumbuhan khas yang biasa hidup di kawasan pantai. Adapun hasil pengamatan di lokasi penelitian jenis vegetasi yang di jumpai adalah sebagai berikut : 
Tabel 3. Jenis - Jenis Vegetasi Pantai di TWA Tanjung Keluang (Types of Beach Vegetation in Tanjung Keluang Nature Park)

\begin{tabular}{|c|c|c|}
\hline \multicolumn{3}{|c|}{$\begin{array}{ll}\text { Nama Latin } & \text { Keterangan }\end{array}$} \\
\hline 1 & Pandan laut & Pandanus tectorius $\quad$ Perdu \\
\hline 2 & Cemara Laut & Casuarina equisetifolia \\
\hline 3 & Waru Laut & Tespesia populrea \\
\hline 4 & Ketapang & Terminalia catappa \\
\hline 5 & Kangkung-Kangkungan & Ipomea pes-caprae \\
\hline \multicolumn{3}{|c|}{ Keberadaan vegetasi } \\
\hline pan & i Tanjung Keluang berperan & yang tidak kuat serta akar dari pohon \\
\hline & ng dalam perkembangbiakan bagi & tersebut dapat membantu dalam proses \\
\hline & sisik. Vegetasi pantai $\mathrm{m}$ & penggalian sarang agar tidak mudah \\
\hline & aga kondisi suhu udara & runtuh. Selain vegetasi, TWA Tanjung \\
\hline & ababan udara serta mampu & Keluang merupakan tempat dari \\
\hline & ga kestabilan suhu di dalam & berbagai satwa, diantaranya adalah \\
\hline & penyu. Dari semua sarang yang & satwa yang menjadi predator bagi penyu \\
\hline & pai pada lokasi penelitian berada & sisik, diantaranya adalah kepiting hantu \\
\hline & $\begin{array}{l}\text { itar vegetasi terutama jenis pohon } \\
\mathrm{n} \text { (Pandanus tectorius). Pohon }\end{array}$ & $\begin{array}{l}\text { (Ocypoda sp), dan biawak (Varanus } \\
\text { salvator). }\end{array}$ \\
\hline
\end{tabular}

Tabel 4. Jenis - Jenis Satwa di TWA Tanjung Keluang (Types of Animals in Tanjung Keluang Nature Park)

\begin{tabular}{rll}
\hline No & Nama Daerah & Nama Latin \\
\hline 1 & Beruang Madu & Helarctos malayanus \\
2 & Orangutan & Pongo pgynaeus \\
3 & Bekantan & Nasalislarvatus \\
4 & Kera Ekor Panjang & Macaca facicularis \\
5 & Babi hutan & Sus scrofa \\
6 & Elang Bondol & Haliatus indus \\
7 & Elang Laut & Haliaeetusleucogaster \\
8 & Biawak & Varanus salvator \\
9 & Kepiting Hantu & Ocypoda sp \\
10 & Pesut & Orcaella brevirostis \\
\hline \multicolumn{1}{c}{ Selain ancaman yang ditimbulkan } & Perburuan secara langsung untuk \\
dari faktor aktivitas pemangsa, ancaman & mengambil induk penyu sisik belum \\
lain adalah aktivitas manusia, yaitu & pernah terjadi, akan tetatapi aktivitas \\
antara lain aktivitas pengerukan dasar & manusia seperti pemasangan pukat di \\
laut yang dapat menyebabkan abrasi, & laut berpengaruh terhadap kelestarian \\
aktivitas penangkapan ikan di sekitar & penyu. \\
lokasi peneluran dengan menggunakan & Wawancara \\
jaring dan renggek yang dapat & Dari hasil interview dengan Staff \\
menyebabkan terhambatnya induk & dan Ranger (Penjaga pantai) TWA \\
penyu pada saat akan naik ke pantai, & Tanjung Keluang merupakan kawasan \\
keberadaan sampah, serta berkurangnya & pelestarian alam juga sebagai tempat \\
luas permukaan pasir pantai akibat dari & rekreasi yang dikelola oleh BKSDA \\
banyaknya tumbuhan rumput liar yang & SKW-II Pangkalan Bun Kalimantan \\
hidup dipermukaan pasir pantai. &
\end{tabular}


Tengah serta menjadi tempat pelestarian penyu sisik. Pengelolaan terkait dengan kelestarian penyu dilakukan dengan membuat sarang semi alami bagi telur telur penyu sisik dan apabila telah menetas baru kemudian dilepaskan kembali ke alam.

Pengelolaan tersebut belum dapat dilakukan secara optimal dikarenakan belum terbentuknya pembagian blok kawasan seperti areal khusus rekreasi, free fishing area, yang mendukung dalam pengelolaan. Sarana prasana untuk melakukan patroli juga masih sangat terbatas melihat dari luasnya kawasan TWA Tanjung Keluang yang cukup luas. Kesadaran masyarakat akan kelestarian penyu sisik menjadi salah satu bagian penting dalam kelestarian, karena masyarakat sekitar masih kerap kali mengambil telur penyu sisik untuk dikonsumsi.

\section{Ancaman}

Ancaman kelestarian penyu berasal dari hewan pemangsa telur penyu seperti, biawak (Varanus salvator), kepiting hantu (Ocypoda sp.), pengaruh alam seperti, Abrasi Pantai, penurunan kualitas habitat peneluran oleh sampah, penurunan luas lokasi peneluran akibat keberadaan rumput liar, dan juga oleh manusia seperti aktifitas menangkap ikan dengan menggunakan alat tangkap yang dapat membahayakan penyu seperti Rawai.

\section{Kesimpulan}

1. Karakteristik abiotik di lokasi peneluran bagi penyu sisik diantaranya adalah memiliki panjang pantai \pm 5000 meter, tipe pantai berpasir dengan lebar pantai saat air pasang tertinggi berkisar antara 3 -
12 meter sedangkan pada saat air surut terendah berkisar antara $9-20$ meter. Tekstur pasir berukuran sedang berkisar antara 0,21 - 0,50 $\mu \mathrm{m}$, dan kemiringan pantai berkisar antara $10-15 \%$.

2. Karakteristik biotik di lokasi peneluran diantaranya adalah vegetasi pantai didominasi oleh Pandan laut (Pandanus tectorius), Cemara Laut (Casuarina equisetifolia), Waru Laut (Thespesia populnea), Ketapang (Terminalia catappa) dan kangkung kangkungan (Ipomoea pes-caprae).

\section{Saran}

Taman Wisata Alam Tanjung Keluang merupakan kawasan untuk pariwisata alam dimana terdapat salah satu jenis penyu yang dilindungi yaitu Penyu Sisik, maka sebaiknya dibentuk blok pemanfaatan kawasan. Blok pemanfaatan tersebut dapat berupa kawasan yang diperuntukan untuk rekreasi, peneluran penyu, dan kawasan bebas bagi berbagai aktifitas nelayan (free fishing area), sehingga aktifitas wisatawan tidak mengganggu habitat bertelur bagi penyu sisik serta dapat menjaga keberlanjutan peneluran di Taman Wisata Alam Tanjung Keluang, serta edukasi kepada masyarakat yang tinggal di sekitar lokasi tentang konservasi penyu sisik dan kelestarian lingkungan.

\section{DAFTAR PUSTAKA}

Balai Konservasi Sumber Daya Alam, Kal-Teng 2011. Tentang Taman Wisata Alam Tanjung Keluang http://bksdakalteng.dephut.go.id 
diakses tanggal 30 september 2015 .

Ewart, M.A. 1979. The Embryo and its eggs;Development and Natural History h.333-416. In M.harless dan H,Morlock(Eds), Turtles, perspectif and research. John Wiley and Sons,Inc.New York

Hutabarat dan Evans, 2001. Pengantar Oseanografi. Universitas Indonesia Press. Jakarta.

Nuitja, 1992. Biologi dan Ekologi Pelestarian Penyu Laut. Institut Pertanian Bogor (IPB): Bogor.

Rahma, M. 2012. Parameter Pengukuran Kualitas Air. http://rmmulyani.blogspot.co.id.pa rameter kualitas air.html. diakses tanggal 19 Mei 2016

Richayasa, A. 2015. Karakteristik Habitat Peneluran Penyu Sisik (Eretmachelys imbricata) Di Pulau Geleang, Karimunjawa. Fakultas Matematika Dan Ilmu Pengetahuan Alam, Universitas Negeri Semarang. Semarang.

Rohim H, Rifanjani S, Erianto, 2017. Studi Habitat Tempat Bertelur Penyu Hijau (Chelonia mydas) Di Kawasan Tambling Wildlife
Nature Conservation (TWNC) Taman Nasional Bukit Barisan Selatan (TNBBS) Tanggamus Pesisir Barat. Hutan Lestari, 5 (2) : 313 - 318

Setiawan R, Zamdial, Fajar B.SPN, 2018. Studi Karakteristik Habitat Peneluran Penyu Di Desa Pekik Nyaring Kecamatan Pondok Kelapa Kabupaten Bengkulu Tengah, Provinsi Bengkulu. Ilmu Kelautan Kepulauan, 1 (1) : 59 70

Setyawatiningsih S.R, Marniasih D, Wijiyanto, 2011. Karakteristik Biofisik Tempat Peneluran Penyu Sisik (Eretmochelys imbricata) Di Pulau Anak Ileuh Kecil, Kepulauan Riau, II (1) : 17 - 22

Syamsuni, 2005. Karakteristik Habitat Dan Penyebaran Sarang Penyu Sisik (Eretmochelys imbricata, Linnaeus 1758) Studi Kasus Pulau Burung, Kepulauan Karimunjawa, Jawa Tengah. Institue Pertanian Bogor. Bogor

Yusuf, A. 2000.Mengenal Penyu. Yayasan Alam Lestari Jakarta 